\title{
Effect of phenolic aldehydes and flavonoids on growth and inactivation of Oenococcus oeni and Lactobacillus hilgardii
}

\author{
Ana Rita Figueiredo ${ }^{\mathrm{a}}$, Francisco Campos ${ }^{\mathrm{a}}$, Víctor de Freitas ${ }^{\mathrm{b}}$, \\ Tim Hogg ${ }^{\mathrm{a}}$, José António Couto ${ }^{\mathrm{a}, *}$ \\ ${ }^{a}$ Escola Superior de Biotecnologia, Universidade Católica Portuguesa, Rua Dr. António Bernardino de Almeida, 4200-072 Porto, Portugal \\ ${ }^{\mathrm{b}}$ Faculdade de Ciências do Porto, Departamento de Química, Centro de Investigação em Química, Rua do Campo Alegre 687, 4169-007 Porto, Portugal
}

Keywords: Lactic acid bacteria; Phenolic aldehydes; Flavonoids; Tannins; Wine

\begin{abstract}
The aim of this work was to investigate the effect of wine phenolic aldehydes, flavonoids and tannins on growth and viability of strains of Oenococcus oeni and Lactobacillus hilgardii. Cultures were grown in ethanol-containing MRS/TJ medium supplemented with different concentrations of phenolic aldehydes or flavonoids and monitored spectrophotometrically. The effect of tannins was evaluated by monitoring the progressive inactivation of cells in ethanol-containing phosphate buffer supplemented with grape seed extracts with different molecular weight tannins. Of the phenolic aldehydes tested, sinapaldehyde, coniferaldehyde, $p$-hydroxybenzaldehyde, 3,4dihydroxybenzaldehyde and 3,4,5-trihydroxybenzaldehyde significantly inhibited the growth of $O$. oeni VF, while vanillin and syringaldehyde had no effect at the concentrations tested. Lact. hilgardii 5 was only inhibited by sinapaldehyde and coniferaldehyde. Among the flavonoids, quercetin and kaempferol exerted an inhibitory effect especially on $O$. oen $i$ VF. Myricetin and the flavan-3-ols studied (catechin and epicatechin) did not affect considerably the growth of both strains. Condensed tannins (particularly tetramers and pentamers) were found to strongly affect cell viability, especially in the case of $O$. oen $\mathrm{VF}$. In general, this strain was found to be more sensitive than Lact. hilgardii 5 to the phenolic compounds studied. This work contributes to the knowledge of the effect of different phenolic compounds on the activity of wine lactic acid bacteria, which, especially in the case of aldehydes and of different molecular weight fractions of tannins, is very scarce.
\end{abstract}

Introduction

Wine is a harsh environment for microorganisms, mainly due to its low $\mathrm{pH}$, low availability of nutrients and the presence of ethanol and sulphur dioxide. However, certain microorganisms, among which some genera of lactic acid bacteria, have the ability to tolerate the wine stresses (Fleet et al., 1997). In wine, these bacteria, which occur in four genera (Oenococcus, Pediococcus, Lactobacillus and Leuconostoc), can have a positive effect, being responsible for the malolactic fermentation, but can also have deleterious effects, being responsible for a range of wine spoilage

\footnotetext{
*Corresponding author. Fax: + 351225580111.

E-mail address: jacouto@esb.ucp.pt (J.A. Couto).
}

conditions. In the malolactic fermentation the main reaction is the decarboxylation of L-malic acid to L-lactic acid, leading to deacidification, flavour modification and increased microbial stability of wine (Henick-Kling, 1993). Oenococcus oeni is the main lactic acid bacteria responsible for the malolactic fermentation, being often chosen as a starter culture in commercial wine applications (Van Vuuren and Dicks, 1993; Coucheney et al., 2005). Wine spoilage can be a consequence of the unrestrained growth of lactic acid bacteria and depending on the wine and bacterial species, different types of faults can take place (Sponholz, 1993). The genus Lactobacillus is often involved in the spoilage of wines; particularly, the species Lactobacillus hilgardii has been identified as a major cause of spoilage of fortified wines (Couto and Hogg, 1994; de Revel et al., 1994). 
Phenolic compounds have a major contribution to the sensory characteristics of wines, namely colour, mouthfeel, bitterness and astringency. These compounds, which derive from grape material (skins, seeds and stalks) and from the wood used in wine storage (Ribéreau-Gayon et al., 2000), can be divided into two groups: non-flavonoids (which includes phenolic acids, aldehydes and alcohols) and flavonoids (comprising anthocyanins, flavonols and flavanols) (Macheix et al., 1990). Most non-flavonoids have a simple structure (Fig. 1), possessing one or more hydroxy and methoxy groups directly bound to the benzene ring. Phenolic aldehydes are structurally similar to phenolic acids and originate from the degradation of lignins in wood cooperage (Jackson, 2000). Flavonoids possess the flavilium ring $\mathrm{C}_{6}-\mathrm{C}_{3}-\mathrm{C}_{6}$ as structural backbone (Fig. 1). Among them, the flavon-3-ols are present mainly in the glycoside form and can be differentiated according to the hydroxylation of the B-ring: kaempferol $(1 \mathrm{OH})$, quercetin $(2 \mathrm{OH})$ and myricetin (3 OH) (Macheix et al., 1990; Ribéreau-Gayon et al., 2000). The most important flavan3 -ols in wine are $(+)$-catechin and (-)-epicatechin, which are the basic units of procyanidins and condensed tannins (Macheix et al., 1990). Unlike flavon-3-ols, flavan-3-ols have a characteristic saturated C-ring. Tannins are defined as polymers with undefined and complex structure capable

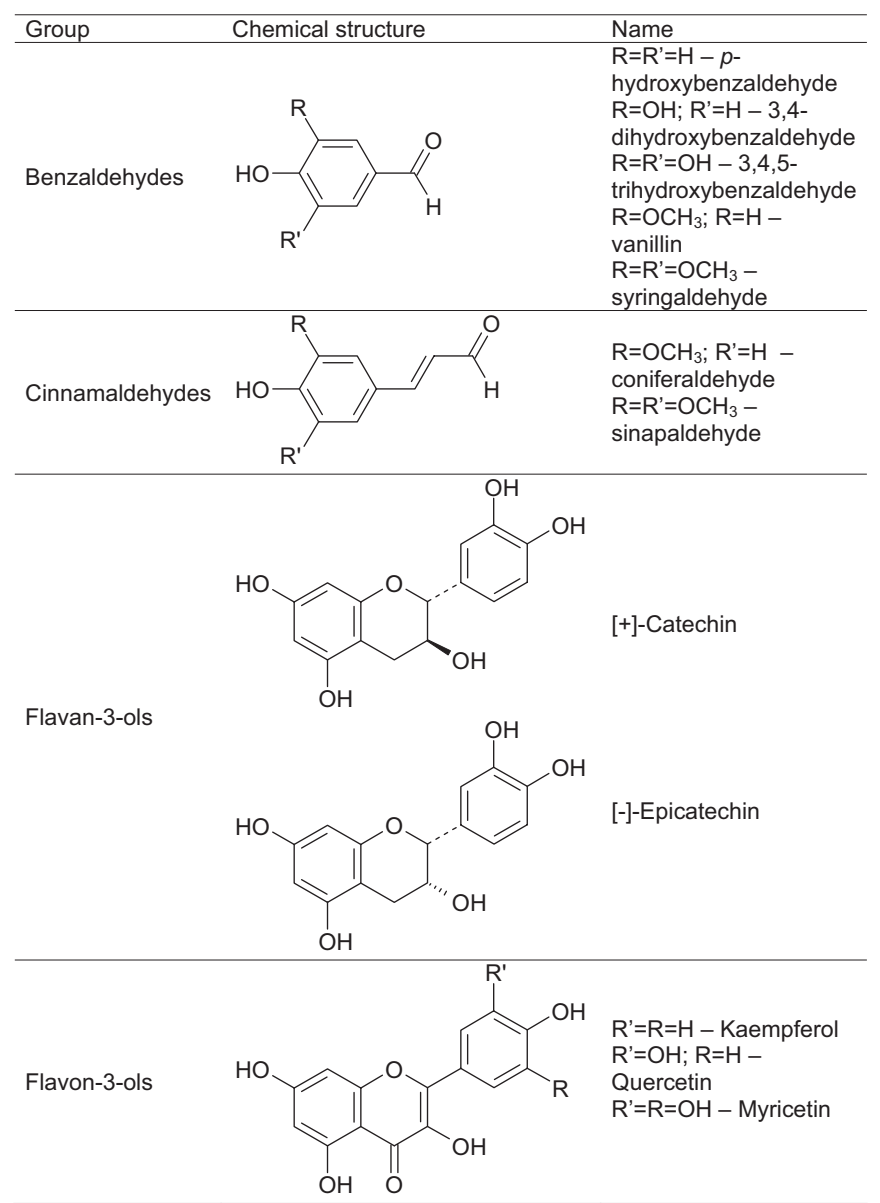

Fig. 1. Chemical structure of phenolic compounds. of producing stable interactions with proteins and other plant polymers such as polysaccharides. Depending on their basic structural unit, tannins can be divided into hydrolysable tannins (with gallic acid, ellagic acid or its derivates as monomers) and condensed or catechic tannins (with catechins and epicatechins as monomers) (Macheix et al., 1990; Ribéreau-Gayon et al., 2000).

Some studies started to unveil the biological effect of phenolic compounds on wine microorganisms. It has been found that phenolic extracts from wood and wines have a stronger influence on the growth of microorganisms than some of their individual components (Vivas et al., 2000; Papadopoulou et al., 2005). The influence of these compounds on lactic acid bacteria remains unclear; while some stimulate bacterial growth and activity, others have an inhibitory effect. It has been described that catechin stimulates the growth and the malolactic fermentation activity of $O$. oeni and Lact. hilgardii (Reguant et al., 2000; Alberto et al., 2001). Vivas et al. (2000) found that procyanidins adversely affected the viability of $O$. oeni. Some phenolic acids were found to influence negatively the growth and survival of wine lactic acid bacteria (Stead, 1993; Campos et al., 2003). Phenolic aldehydes have been found to exert a toxic effect on microorganisms (Barber et al., 2000; Puupponen-Pimiä et al., 2001; Friedman et al., 2003; Fitzgerald et al., 2004; Gill and Holley, 2004) but very little is known about its action on wine bacteria.

In the present work, we studied the effect of phenolic aldehydes, flavonols, flavanols and tannins on the growth or cell viability of $O$. oeni $\mathrm{VF}$ and Lact. hilgardii 5 . This is, to our knowledge, the first work employing different molecular weight fractions (obtained from grape seed extractions) to study the influence of tannins on the cell viability of wine lactic acid bacteria.

\section{Materials and methods \\ Bacteria and growth conditions}

Lact. hilgardii strain 5, isolated by Couto and Hogg (1994), from the ESBUCP (Escola Superior de Biotecnologia da Universidade Católica Portuguesa, Porto, Portugal) culture collection and $O$. oeni commercial strain VINIFLORA OENOS from Christian Hansen (Hrevidre, Denmark), were employed in this study. Lact. hilgardii strain 5 was chosen for being taxonomically representative of the predominant ethanol-tolerant species found in Port wine (Couto, 1996; Couto and Hogg, 1994).

The liquid growth medium used in this experiment (MRS/TJ) is a mixture (50:50) of two commercial media: MRS (de Man, Rogosa and Sharpe) from Biokar Diagnostics (Beauvais, France) and TJ (Tomato Juice broth) from Difco (Detroit, USA). The initial pH was adjusted to 4.5 with a concentrated $\left(6 \mathrm{~mol} \mathrm{~L}^{-1}\right)$ hydrochloric acid solution. Ethanol $(99.5 \%, \mathrm{v} / \mathrm{v})$ was added to the medium after sterilization $\left(121^{\circ} \mathrm{C}, 15 \mathrm{~min}\right)$ to obtain a final concentration of $5 \%(\mathrm{v} / \mathrm{v})$. This concentration of 
ethanol in the culture medium was found to stimulate the growth of these organisms (Couto, 1996). Cultures were grown aerobically, without agitation at $25^{\circ} \mathrm{C}$.

Inuence of phenolic aldehydes and flavonoids on the growth of $\mathrm{O}$. oeni and Lact. hilgardii

Cultures were grown to late exponential phase in MRS/ TJ with $5 \%(\mathrm{v} / \mathrm{v})$ ethanol and then transferred to liquid MRS/TJ containing phenolic compounds (aldehydes and flavonoids). All these compounds were obtained from Sigma-Aldrich (Steinheim, Germany). Phenolic aldehydes - vanillin, syringaldehyde, coniferaldehyde, sinapaldehyde, $p$-hydroxybenzaldehyde, 3,4-dihydroxybenzaldehyde and 3,4,5-trihydroxybenzaldehyde - were used at concentrations levels of 0,250 and $500 \mathrm{mg} \mathrm{L}^{-1}$. Flavon-3-ols (quercetin, myricetin and kaempferol) were added at 0,10 , 20 and $40 \mathrm{mg} \mathrm{L}^{-1}$ and flavan-3-ols at $0,12.5,25$ and $50 \mathrm{mg} \mathrm{L}^{-1}$ for (+)-catechin and at 3.12, 6.25 and $12.5 \mathrm{mg} \mathrm{L}^{-1}$ for (-)-epicatechin. The purity of the compounds was at least $97 \%$, except for kaempferol $(90 \%)$, myricetin $(85 \%)$ and $(-)$-epicatechin $(>90 \%)$. The disparity in the concentrations used was due to different levels of solubility of the flavonoids in the culture medium used. Fresh concentrated solutions of these compounds were prepared in pure $(99.5 \%, \mathrm{v} / \mathrm{v})$ ethanol and added to the growth media and the final ethanol concentration was adjusted to $5 \%(\mathrm{v} / \mathrm{v})$. Each individual assay was made in triplicate and incubated aerobically, without agitation at $25^{\circ} \mathrm{C}$. The whole experiment was repeated to verify the results.

Bacterial growth was determined by measuring the culture medium absorbance at $660 \mathrm{~nm}$, using an $\mathrm{UV} /$ vis UNICAM 8620 spectrophotometer (UNICAM, Cambridge, UK).

Inuence of tannins on the survival of $\mathrm{O}$. oeni and Lact. hilgardii

Condensed tannins used were extracted from Vitis vinifera grape seed tissues, according to the method described by de Freitas et al. (2003). Polyphenols were extracted from grape seed tissues $(5 \mathrm{~g})$ with $50 \mathrm{~mL}$ of an ethanol/water/chloroform solution $(1: 1: 2, \mathrm{v} / \mathrm{v} / \mathrm{v})$ using a blender. The upper aqueous layer containing the polyphenols was separated from the chloroform layer containing chlorophylls, lipids and other undesirable compounds. Ethanol was removed from the hydroalcoholic layer on a rotary evaporator at $30^{\circ} \mathrm{C}$ and polyphenol compounds were extracted from the resulting aqueous solution with ethyl acetate $(3 \times 20 \mathrm{~mL})$. The volume of ethyl acetate was reduced to $10 \mathrm{~mL}$ on a rotary evaporator at $30^{\circ} \mathrm{C}$ and the condensed tannins were obtained by precipitation with $15 \mathrm{~mL}$ of hexane. The resulting solid was purified by column chromatography (TSK Toyopearl HW-40(s) gel) to yield catechin monomers and polymeric procyanidin fractions. These fractions were directly analysed by
LSI/MS. The composition of the different fractions is as follows: Fraction A: catechins $\left([\mathrm{M}+\mathrm{H}]^{+}\right.$at $\left.m / z=291\right)$, catechins-gallate (443) and dimers (579); fraction B: dimers-gallate $(579,731)$, trimers $(867)$, trimers-gallate (1019) and tetramers (1155); fraction C: tetramers-gallate $(731,867,1019,1155,1307)$ and pentamers $(1443)$; fraction D: tetramers-digallate (1459) and pentamers-gallate (1595).

The effect of tannins on the inactivation of $O$. oen $\mathrm{VF}$ and Lact. hilgardii 5 was tested in a phosphate buffer solution $\left(\mathrm{KH}_{2} \mathrm{PO}_{4}, 0.15 \mathrm{M}, \mathrm{pH} \quad 4.5\right)$ with $10 \%(\mathrm{v} / \mathrm{v})$ ethanol. Cultures in stationary phase, grown aerobically without agitation for 4 days in MRS/TJ with $5 \%(\mathrm{v} / \mathrm{v})$ ethanol at $25^{\circ} \mathrm{C}$, were centrifuged $(10 \mathrm{~min}, 3000 \mathrm{~g})$. The pellet was washed with phosphate buffer containing 5\% (v/v) ethanol and centrifuged again. Cells were resuspended in phosphate buffer containing $5 \%(\mathrm{v} / \mathrm{v})$ ethanol. One millilitre of this suspension was transferred to $100 \mathrm{~mL}$ of phosphate buffer ( $1 \%$ inoculum) containing $10 \%(\mathrm{v} / \mathrm{v})$ ethanol and the tannin fraction at $500 \mathrm{mg} \mathrm{L}^{-1}$, in $250 \mathrm{~mL}$ Erlenmeyer flasks. These were stirred magnetically and immersed in a thermostatted water bath at $25^{\circ} \mathrm{C}$. Two flasks were used as controls, one containing $100 \mathrm{~mL}$ of phosphate buffer and the other containing the buffer with added $10 \%(\mathrm{v} / \mathrm{v})$ of ethanol. After the inoculation of the phosphate buffer, samples were collected at $5 \mathrm{~s}, 5,15,30,45$ and $60 \mathrm{~min}$, properly diluted and plated in duplicate on MRS/TJ media containing $20.0 \mathrm{~g} \mathrm{~L}^{-1}$ Agar MC2 (LAB M, Bury, UK) and $5 \%(\mathrm{v} / \mathrm{v})$ ethanol. Plates were incubated aerobically at $25^{\circ} \mathrm{C}$ for $5-7$ days. The whole experiment was repeated for each fraction of tannins and bacterium, to confirm the results.

\section{Statistical analysis}

All bacterial growth curves were analysed by non-linear regression (fitting Gompertz equation) for the independent estimation of growth parameters $(\mu$, maximum growth rate; $\mathrm{OD}_{\max }$, maximum cell density). One-way analysis of variance (ANOVA) was used to test the effect of phenolic compounds' concentration on growth parameters, and post hoc Tukey test was used for multiple mean comparisons. All statistical analyses were performed with Prism 4 vs. 4.0a (GraphPad Software Inc.).

\section{Results}

Effect of phenolic aldehydes on the growth of O. oeni and Lact. hilgardii

At the levels normally found in wines $\left(1-2 \mathrm{mg} \mathrm{L}^{-1}\right)$, phenolic aldehydes did not exert effect on the growth of the microorganisms studied (data not shown). The effect of these compounds were then studied at higher concentrations. From the phenolic aldehydes tested it can be seen that sinapaldehyde, coniferaldehyde, $p$-hydroxybenzaldehyde, 3,4-dihydroxybenzaldehyde and 3,4,5-trihydroxybenzaldehyde inhibited the growth of $O$. oeni VF (Fig. 2). 
a

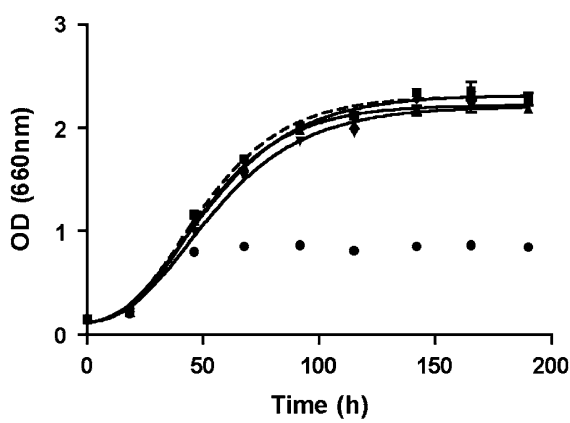

b

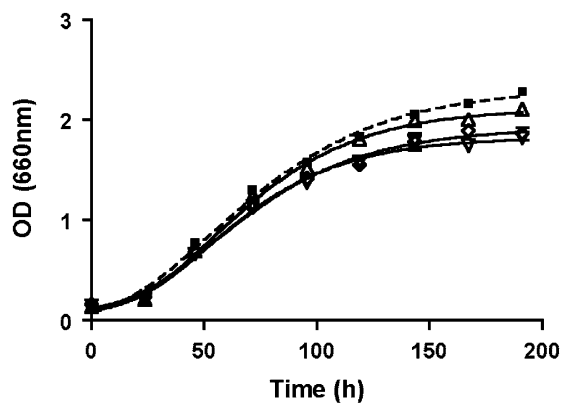

C

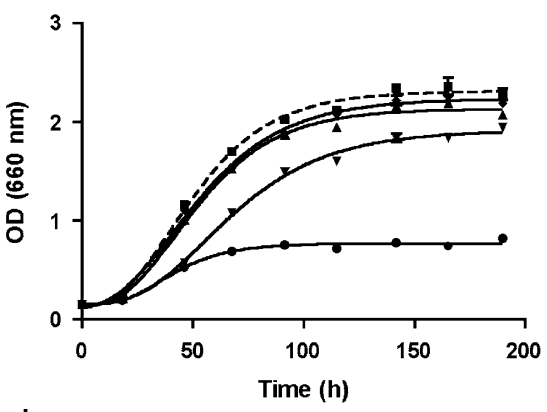

d

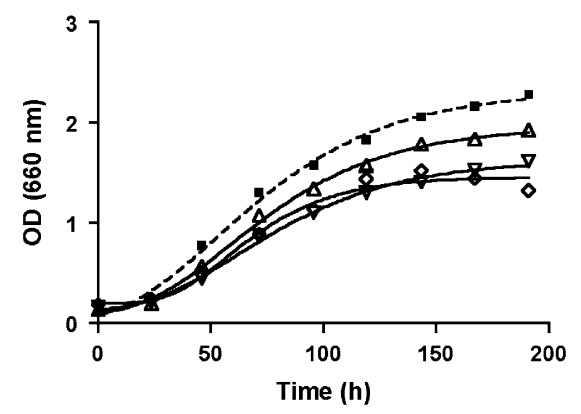

Fig. 2. Growth curves of Oenococcus oeni VF in MRS/TJ media ( $\mathrm{pH} 4.5,5 \%(\mathrm{v} / \mathrm{v})$ ethanol at $\left.25^{\circ} \mathrm{C}\right)$ supplemented with phenolic aldehydes at (a and b)

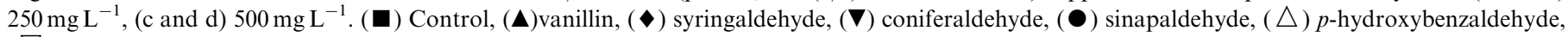
$(\nabla)$ 3,4-dihydroxybenzaldehyde, $(\diamond)$ 3,4,5-trihydroxybenzaldehyde. Each point represents the average value of three determinations; vertical bars represent standard deviation for each set of determinations.

The highest effect was that of sinapaldehyde, clearly observed in both concentrations used, with a strong impact on the final cell density $(P<0.001)$. The fitted line was omitted from the graph due to the poor fitting obtained with Gompertz equation. As we can see from data distribution, this fact was probably caused by the short number of empirical values on the initial range of the exponential growth phase. The effect of coniferaldehyde was significant only at $500 \mathrm{mg} \mathrm{L}^{-1}(P<0.001)$. The effect of the other phenolic aldehydes is also dose dependent and caused a significant decrease in the final cell density when compared to the control culture $(P<0.01)$. Vanillin and syringaldehyde did not affect the growth of this bacterium at the concentrations tested (Fig. 2).

A decrease in the growth rate of Lact. hilgardii 5 in the presence of sinapaldehyde $(P<0.01)$ and coniferaldehyde $(P<0.001)$ was detected when the compounds were tested at $500 \mathrm{mg} \mathrm{L}^{-1}$ (Fig. 3c and d). This strain was not significantly affected by the presence of the other phenolic aldehydes tested.

\section{Effect of flavonoids on the growth of $\mathrm{O}$. oeni and Lact. hilgardii}

The flavon-3-ols quercetin and kaempferol exerted a strong inhibitory dose-dependent effect on the growth of O. oeni VF (Fig. 4a-c). A marked decrease of the growth rate $(P<0.001$ for quercetin; $P<0.01$ for kaempferol $)$ and of the final biomass $(P<0.001)$ was obtained. Myricetin had no noticeable effect on the growth of this strain.
No significant effect was observed in the growth of Lact. hilgardii 5 in the presence of flavon-3-ols at 10 and $20 \mathrm{mg} \mathrm{L}^{-1}$ (Fig. $4 \mathrm{~d}$ and e). At $40 \mathrm{mg} \mathrm{L}^{-1}$, quercetin and kaempferol significantly decreased the growth rate $(P<0.05)$ and increased the final cell density $(P<0.001)$ (Fig. 4f).

None of the flavan-3-ols tested in this experiment (catechin and epicatechin) significantly affected the growth of O. oeni VF or Lact. hilgardii 5 (data not shown).

\section{Inactivation of $\mathrm{O}$. oeni and Lact. hilgardii by tannins}

The influence of tannins on cell physiology was studied by the progressive inactivation of cells in ethanol-containing phosphate buffer supplemented with different tannin fractions. Growth assays were not carried out since the tannins were found to be difficult to solubilise in the culture medium probably due to the interaction with proteins. All fractions of tannins tested led to a marked decrease in the number of viable cells of $O$. oen $i \mathrm{VF}$, causing a reduction of $4 \log$ cycles or more (Fig. 5a). It was also noted that the inactivation effect increases with the increment of the average tannin size in the fractions (from A to C). A similar behaviour was found for Lact. hilgardii 5 but with a milder effect. Fraction A did not show a noticeable inactivation and fraction $\mathrm{C}$ caused a $2.5 \mathrm{log}$ cycles reduction in $60 \mathrm{~min}$ (Fig. 5b). In both strains the highest effect was obtained when cells were treated with fraction $\mathrm{C}$. The control experiment performed in buffer with $10 \%(\mathrm{v} / \mathrm{v})$ ethanol did not affect the survival of both strains. Cells exposed to the 

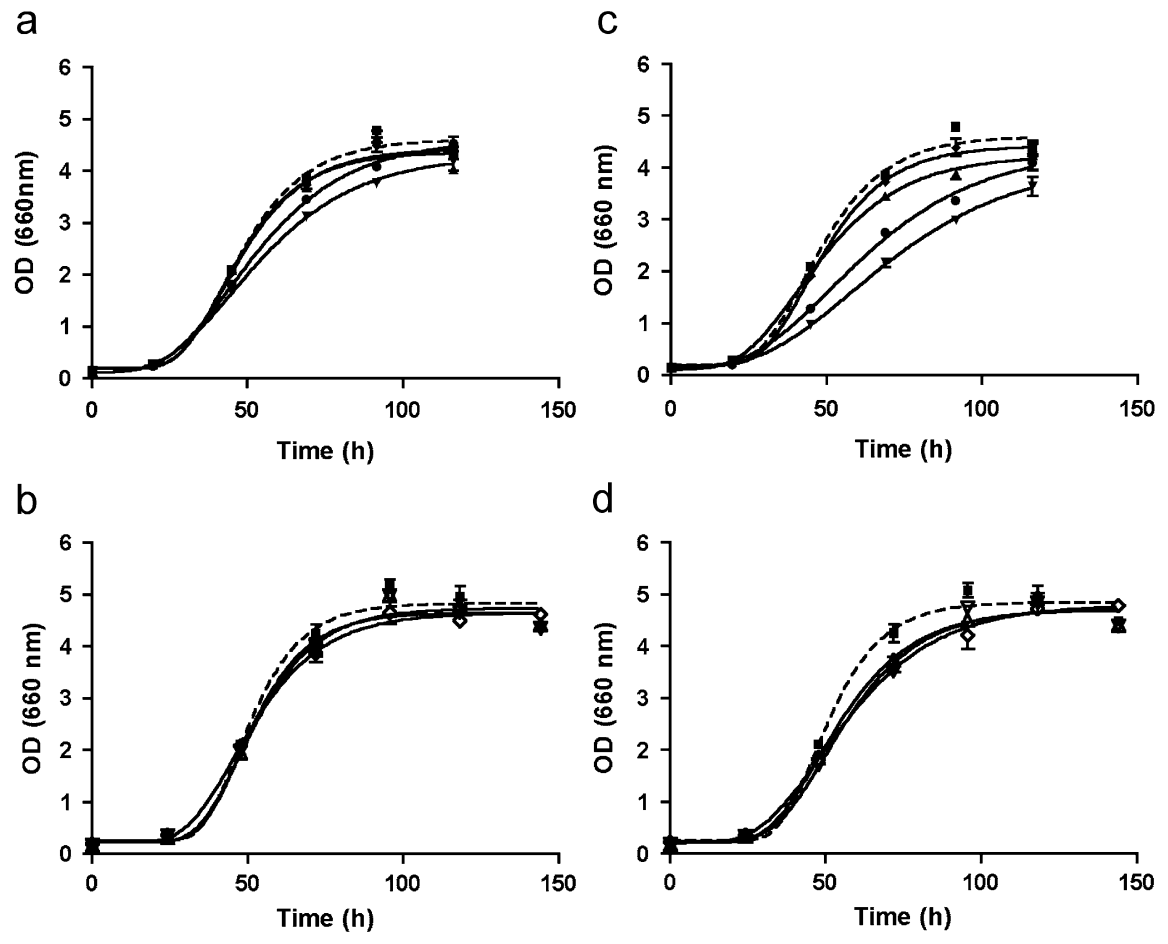

Fig. 3. Growth curves of Lactobacillus hilgardii 5 in MRS/TJ media ( $\mathrm{pH} 4.5,5 \%$ (v/v) ethanol at $\left.25^{\circ} \mathrm{C}\right)$ supplemented with phenolic aldehydes at (a and b) $250 \mathrm{mg} \mathrm{L}^{-1}$, (c and d) $500 \mathrm{mg} \mathrm{L}^{-1}$. ( $\left.\mathbf{\square}\right)$ Control, $(\boldsymbol{\Delta})$ vanillin, $(\diamond)$ syringaldehyde, ( $)$ coniferaldehyde, $(\bullet)$ sinapaldehyde, $(\triangle) p$-hydroxybenzaldehyde, $(\nabla)$ 3,4-dihydroxybenzaldehyde, $(\diamond)$ 3,4,5-trihydroxybenzaldehyde. Each point represents the average value of three determinations; vertical bars represent standard deviation for each set of determinations.

different tannin fractions were observed under the light microscope after 30 and $60 \mathrm{~min}$ of exposure. Clumping effects were not observed in both strains for the four tannin fractions experimented. Cells were found to be homogeneously distributed in the liquid in a similar manner as the control culture.

\section{Discussion}

This work provides insight into the effect of various phenolic compounds on wine lactic acid bacteria. Most of the phenolic aldehydes tested influenced the growth of $O$. oeni VF. Cinnamaldehydes (particularly sinapaldehyde) were the ones that most affected growth of this strain by diminishing the growth rate and reducing the final cellular concentration. This inhibitory effect, although less strong, was also observed for some benzaldehydes ( $p$-hydroxybenzaldehyde, 3,4-dihydroxybenzaldehyde and 3,4,5-trihydroxybenzaldehyde). The growth rate of Lact. hilgardii 5 was negatively influenced only by cinnamaldehydes. These results are in accordance with the previous work done by Campos et al. (2003) with structurally similar phenolic (cinnamic and benzoic) acids that only differ from the tested aldehydes in the functional group. The less polar nature of the cinnamaldehydes, due to their propionic side chain, might confer a higher affinity to the lipid content of the bacterial cell membrane (O'Connor and Rubino, 1991), possibly enabling these molecules to move more readily across the outer cell layers. Although several studies already identified cinnamaldehydes as bactericidal agents (Kwon et al., 2003; Gill and Holley, 2004; Kim et al., 2004), their mechanism of action is not yet fully understood and probably varies according to the microorganism. For instance, in Bacillus cereus cinnamaldehyde does not exhibit cell lysis but affect cell viability (Kwon et al., 2003), while in Listeria monocytogenes and Escherichia coli cell membrane disruption was advanced as a possible mechanism of cinnamaldehyde action, dispersing the proton motive force by leakage of small ions (Gill and Holley, 2004; Kim et al., 2004). The number of hydroxyl groups in the benzaldehyde derivates that inhibited the growth of $O$. oeni $\mathrm{VF}$ seems to be related to their inhibitory power. The disubstituted and trisubstituted benzaldehydes had a higher inhibitory effect than $p$-hydroxybenzaldehyde. Benzaldehydes are thought to act primarily on the external surface of the cells, combining with sulphydryl groups of proteins (Ramos-Nino et al., 1998). Ramos-Nino et al. (1996) and Friedman et al. (2003) reported that benzaldehydes with two or more adjacent hydroxyl groups are more active than aldehydes that lack this characteristic, which is in agreement with our results. At the concentrations used in this work (higher than those normally found in wines), vanillin did not affect the growth of both strains. At higher concentrations, however, Fitzgerald et al. (2004) found that vanillin may have antimicrobial activity against $E$. coli, Listeria innocua and Lactobacillus plantarum. According to these authors, vanillin affects the integrity of the cytoplasmic membrane causing loss of ion gradients and $\mathrm{pH}$ 

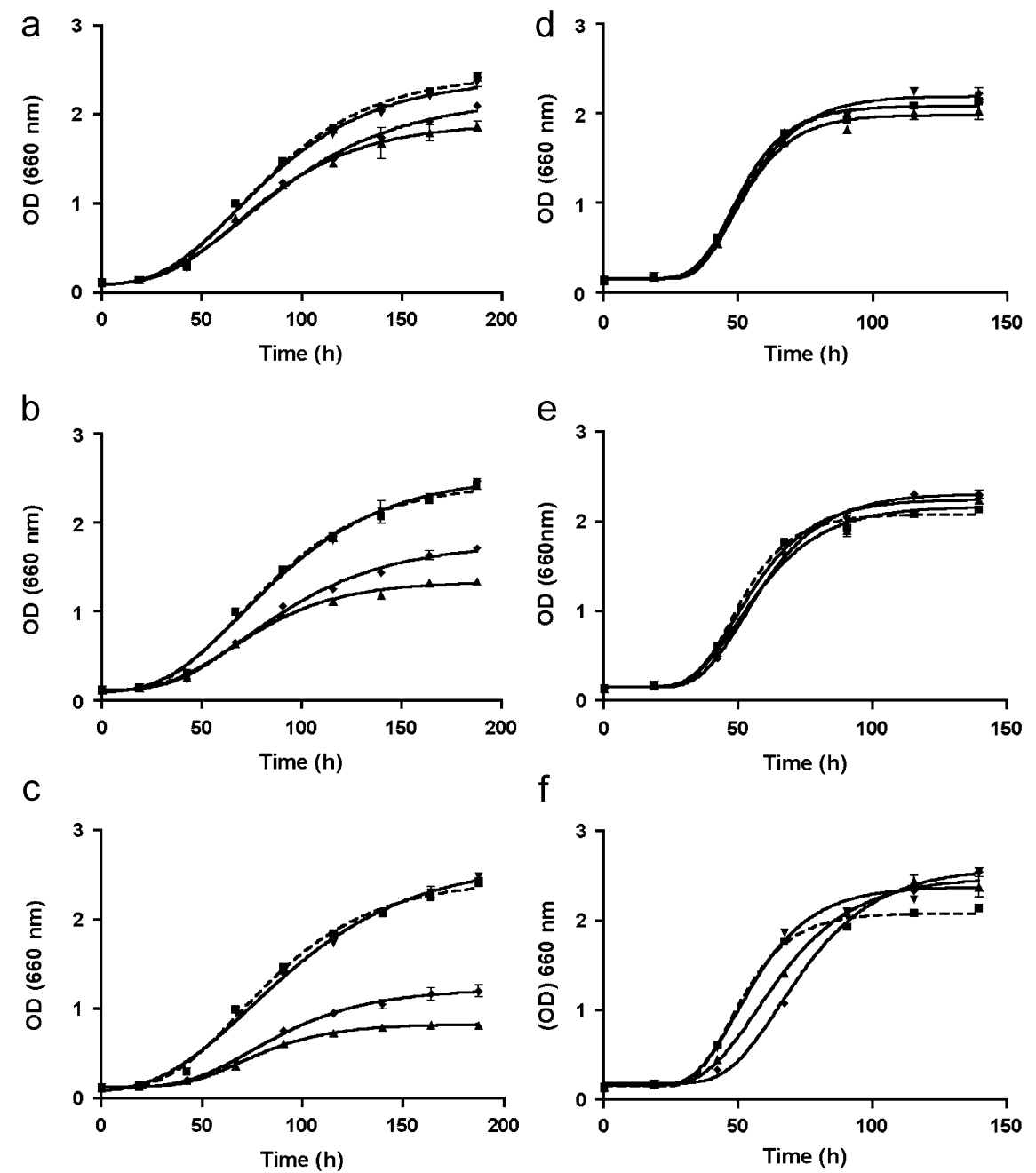

Fig. 4. Growth curves of Oenococcus oeni VF (a-c) and Lactobacillus hilgardii $5(\mathrm{~d}-\mathrm{f})$ in MRS/TJ media ( $\mathrm{pH} 4.5,5 \%$ (v/v) ethanol at $\left.25^{\circ} \mathrm{C}\right)$ supplemented

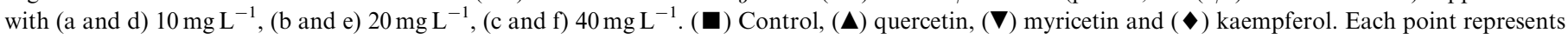
the average value of three determinations; vertical bars represent standard deviation for each set of determinations.
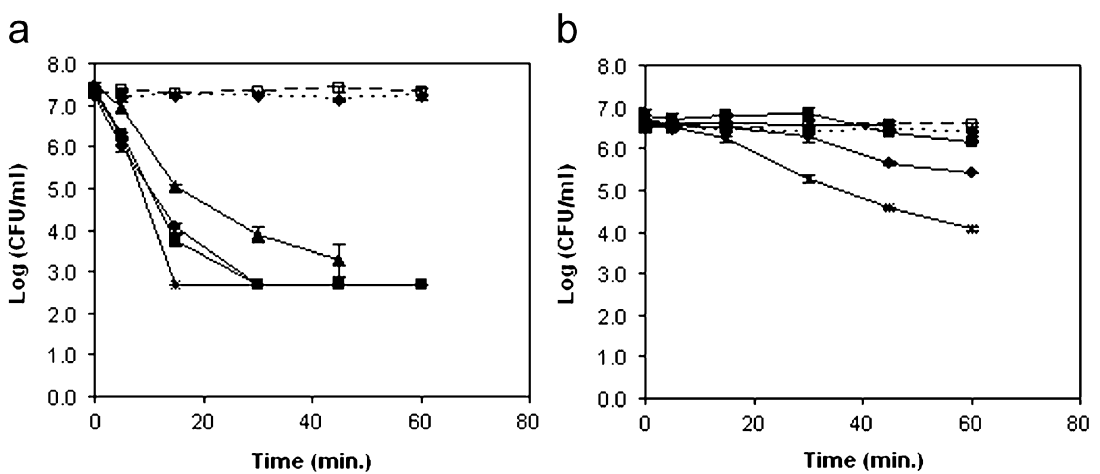

Fig. 5. Inactivation curves of (a) Oenococcus oeni $\mathrm{VF}$ and (b) Lactobacillus hilgardii 5 in phosphate buffer (pH $4.5,10 \%$ (v/v) ethanol) at $25^{\circ} \mathrm{C}$, supplemented with tannins at $500 \mathrm{ppm}$ : $(\bullet)$ control, $(\square)$ control with $10 \%$ ethanol, $(\boldsymbol{\Delta})$ fraction A, ( $\boldsymbol{\square})$ fraction B, (*) fraction C and $(\bullet)$ fraction D. Each point represents the average value of three determinations, except for fraction A, where each point represents the average value of two determinations; vertical bars represent standard deviation for each set of determinations.

homeostasis. However, this effect was non-lethal and depends on the time of exposure, concentration and target organism.
Of the three flavon-3-ols tested, only the ones harbouring B-rings with less hydroxyl substitutions, kaempferol and quercetin, inhibited the growth of $O$. oeni VF. Myricetin 
(with three $\mathrm{OH}$ substitutions) did not influence the growth of this strain at the tested concentration levels. In the case of Lact. hilgardii 5, only the highest concentration $\left(40 \mathrm{~m} \mathrm{~L} \mathrm{~L}^{-1}\right)$ of quercetin and kaempferol slightly decreased the growth rate (the concentration of these compounds in red wine are in the region of $100 \mathrm{mg} \mathrm{L}^{-1}$; Ribéreau-Gayon et al., 2000). Unexpectedly, at the mentioned concentration, the final cell density attained in the presence of the flavon-3-ols, especially quercetin, was higher than that of the control. Flavon-3-ols are known to possess antioxidant properties by acting as oxygen free radical scavengers. This ability is related to the B-ring hydroxyl configuration and is especially enhanced by the presence of a catechol structure in this ring (Heim et al., 2002). Thus, a possible antioxidant effect could be responsible for the extended growth of Lact. hilgardii 5 in the presence of flavon-3-ols. Our results indicate that flavon-3-ol toxicity cannot be directly related to the degree of hydroxylation (and hence, to the polarity) of the B-ring. This could mean that the inhibitory action of these flavonoids could occur from the extracellular environment or that it could be limited by their ability to cross the cell membrane. A similar result was obtained in previous experiments done with phenolic acids (Campos et al., 2003), which suggested that the polarity of the molecules could not explain, by itself, the observed differences in toxicity of these compounds. Quercetin is reported to have antibacterial properties either by inhibiting DNA replication or by acting at the cell membrane level (Cuhsnie and Lambert, 2005). On the other hand, Padmavati et al. (1997) suggested that lipophilicity could be an important factor in flavonoid toxicity. In accordance to this, Puupponen-Pimiä et al. (2001) compared different flavon-3-ols and reported myricetin as being the only inhibitory compound towards lactic acid bacteria from the human gastrointestinal tract flora.

Flavan-3-ols did not affect the growth of the studied bacteria at the concentrations tested, which are within or very close to the levels found in wine $\left(10-200 \mathrm{mg} \mathrm{L}^{-1}\right)$ (Goldberg et al., 1998). It is known that catechin can stimulate the growth of some strains of Lact. hilgardii at the concentrations normally present in wine (Alberto et al., 2001). This stimulation was explained with the ability of these strains to metabolize these classes of phenolic compounds. The absence of stimulus on the growth of the strain used in this work suggests that this ability could be strain dependent. Previous studies also demonstrated that catechin does not have any effect on the growth of several bacterial species (Rauha et al., 2000), including lactic acid bacteria (Puupponen-Pimiä et al., 2001).

The influence of grape seed tannins was evaluated by studying its effect on cell viability in non-growing conditions. It is often claimed that tannins have antiseptic properties, but the scientific data supporting this assertion is very scarce. Our results indicate that some tannin fractions may exert a significant antimicrobial action, clearly seen even at the concentration of $0.5 \mathrm{~g} \mathrm{~L}^{-1}$, which is below the normal level of condensed tannins dissolved in wine (1-4 g L ${ }^{-1}$, depending on grape variety and winemaking procedures; Ribéreau-Gayon et al., 2000). As mentioned above, the condensed tannins' structural units (catechin and epicatechin) did not influence bacterial growth, while it was found that oligomeric and polymeric forms of these compounds exhibit toxic capacities. It is evident, however, that strains of bacteria differ considerably in their tolerance towards tannins, $O$. oen $i \mathrm{VF}$ being much more affected than Lact. hilgardii 5. The results obtained from the viability experiments in non-growing conditions, strongly suggest that the influence of tannins is due to a direct effect on the organisms rather than by the inactivation/precipitation of any essential nutrients. Taking into account their high molecular weight, it might be expected that tannins exert its influence from the extracellular medium. Tannins can bind to membrane phospholipids and proteins disrupting membrane function (Jackson, 2000) or may establish hydrogen links with the peptidoglycan of Gram-positive bacteria cell wall (Field and Lettinga, 1992). In this work, it is perceptible that cell viability decreased with the increment of the tannins size until fraction $\mathrm{C}$, composed by tetramers-gallate and pentamer macromolecules. The effect of fraction $\mathrm{D}$ was less pronounced than fraction $\mathrm{C}$ and similar to fraction $\mathrm{B}$. The results suggest that, to a certain limit, the higher the molecular weight of tannins the higher is its interaction with the cell surface and thus the higher is its effect.

In conclusion, it is demonstrated that different classes of wine phenolic compounds interact with wine lactic acid bacteria. Besides the very well-known effect of parameters like $\mathrm{pH}$, ethanol and sulphur dioxide on microorganisms, the action of phenolic compounds should be considered as a meaningful factor which may influence the growth and activity of lactic acid bacteria in wine. The present work shows that phenolic compounds essentially exhibit microbial inhibitory properties, which may influence the onset and/or the terminus of the malolactic fermentation. Further research is needed to assess whether the phenolic compounds studied also inhibit lactic acid bacteria in real wine conditions.

\section{Acknowledgements}

The authors would like to thank FCT (Fundação para a Ciência e Tecnologia) for funding this research via project POCTI/AGG/40724/2001. F.M. Campos would also like to thank FCT for the grant PRAXIS XXI/BD/19909/99.

\section{References}

Alberto, M.R., Farías, M.E., de Nadra, M.C.M., 2001. Effect of gallic acid and catechin on Lactobacillus hilgardii $5 \mathrm{w}$ growth and metabolism of organic compounds. J. Agric. Food Chem. 49, 4359-4363.

Barber, M.S., McConnell, V.S., DeCaux, B.S., 2000. Antimicrobial intermediates of the general phenylpropanoid and lignin specific pathways. Phytochemistry 54, 53-56. 
Campos, F.M., Couto, J.A., Hogg, T.A., 2003. Influence of phenolic acids on growth and inactivation of Oenococcus oeni and Lactobacillus hilgardii. J. Appl. Microbiol. 94, 167-174.

Coucheney, F., Desroche, N., Bou, M., Tour-Maréchal, R., Dulau, L., Guzzo, J., 2005. A new approach for selection of Oenococcus oeni strains in order to produce malolactic starters. Int. J. Food Microbiol. $105,463-470$.

Couto, J.A., 1996. Ph.D. Thesis, Escola Superior de Biotecnologia da Universidade Católica Portuguesa, Porto, Portugal.

Couto, J.A., Hogg, T.A., 1994. Diversity of ethanol-tolerant lactobacilli isolated from Douro fortified wine: clustering and identification by numerical analysis of electrophoretic protein profiles. J. Appl. Bacteriol. 76, 487-491.

Cuhsnie, T.P., Lambert, A.J., 2005. Antimicrobial activity of flavonoids. Int. J. Antimicrob. Agents 26, 343-356.

de Freitas, V., Carvalho, E., Mateus, N., 2003. Study of carbohydrate influence on protein-tannin aggregation by nephelometry. Food Chem. 81, 503-509.

de Revel, G., Capela, A.B., Hogg, T., 1994. A pre-spoilage marker for bacterial activity in fortified wine, conversion of L-malic acid to L-lactic acid. Lett. Appl. Microbiol. 18, 329-332.

Field, J.A., Lettinga, G., 1992. Toxicity of tannic compounds to microorganisms. In: Hemingway, R.W., Laks, P.E. (Eds.), Plant Polyphenols. Plenum, New York.

Fitzgerald, D.J., Stratford, M., Gasson, M.J., Ueckert, J., Bos, A., Narbad, A., 2004. Mode of antimicrobial action of vanillin against Escherichia coli, Lactobacillus plantarum and Listeria innocua. J. Appl. Microbiol. 97, 104-113.

Fleet, G.H., Doyle, M.P., Beuchat, L.R., Montville, T.J., 1997. Wine. In: Food Microbiology Fundamentals and Frontiers edition. ASM Press, Washington, DC p. 682.

Friedman, M., Henika, P.R., Mandrell, R.E., 2003. Antibacterial activities of phenolic benzaldehydes and benzoic acids against Campylobacter jejuni, Escherichia coli, Listeria monocytogenes and Salmonella enterica. J. Food Prot. 66, 1811-1821.

Gill, A.O., Holley, R.A., 2004. Mechanisms of bactericidal action of cinnamaldehyde against Listeria monocytogenes and eugenol against $L$. monocytogenes and Lactobacillus sakei. Appl. Environ. Microbiol. 70, $5750-5755$.

Goldberg, D.M., Karumanchiri, A., Tsang, E., Soleas, G.J., 1998. Catechin and epicatechin concentrations of red wines: regional and cultivar-related differences. Am. J. Enol. Vitic. 49, 23-34.

Heim, K.E., Tagliaferro, A.R., Bobilya, D.J., 2002. Flavonoid antioxidants: chemistry, metabolism and structure-activity relationships. J. Nutr. Biochem. 13, 572-584.

Henick-Kling, T., 1993. Malolactic fermentation. In: Fleet, G. (Ed.), Wine, Microbiology and Biotechnology. Harwood Academy Publishers, Chur, pp. 289-316.

Jackson, R.S., 2000. Wine Science-Principles, Practice, Perception, second ed. Academic Press, San Diego, pp. 232-270.
Kim, H.O., Park, S.W., Park, H.D., 2004. Inactivation of Escherichia coli O157:H7 by cinnamic aldehyde purified from Cinnamomum cassia shoot. Food Microbiol. 21, 105-110.

Kwon, J.A., Yu, C.B., Park, H.D., 2003. Bacteriocidal effects and inhibition of cell separation of cinnamic aldehyde on Bacillus cereus. Lett. Appl. Microbiol. 37, 61-65.

Macheix, J.J., Fleuriet, A., Billot, J., 1990. Phenolic compounds in fruit processing. In: Fruit Phenolics. CRC Press, Boca Raton, FL pp. 1-91 and $323-332$.

O’Connor, D.O., Rubino, J.R., 1991. Phenolic compounds. In: Block, S.S. (Ed.), Desinfection, Sterilization and Preservation, fourth ed. Lea and Febiger, Philadelphia, pp. 204-224.

Padmavati, M., Sakthivel, N., Thara, K.V., Reddy, A.R., 1997. Differential sensitivity of rice pathogens to growth inhibition by flavonoids. Phytochemistry 46, 499-502.

Papadopoulou, C., Soulti, K., Roussis, I.G., 2005. Potential antimicrobial activity of red and white wine phenolic extracts against strains of Staphylococcus aureus, Escherichia coli and Candida albicans. Food Technol. Biotechnol. 43, 41-46.

Puupponen-Pimiä, R., Nohynek, L., Meier, C., Kähkönen, M., Heinonen, M., Hopia, A., Oksman-Caldentey, K.M., 2001. Antimicrobial properties of phenolic compounds from berries. J. Appl. Microbiol. 90, 494-507.

Ramos-Nino, M.E., Clifford, M.N., Adams, M.R., 1996. Quantitative structure activity relationship for the effect of benzoic acids, cinnamic acids and benzaldehydes on Listeria monocytogenes. J. Appl. Bacteriol. 80, 303-310.

Ramos-Nino, M.E., Ramirez-Rodriguez, C.A., Clifford, M.N., Adams, M.R., 1998. QSARS for the effect of benzaldehydes on foodborne bacteria and the role of sulfhydryl groups as targets of their antibacterial activity. J. Appl. Microbiol. 84, 207-212.

Rauha, J.-P., Remes, S., Heinonen, M., Hopia, A., Kähkönen, M., Kujala, T., Pihlaja, K., Vuorela, H., Vuorela, P., 2000. Antimicrobial effects of finnish plant extracts containing flavonoids and other phenolic compounds. Int. J. Food Microbiol. 56, 3-12.

Reguant, C., Bordons, A., Arola, L., Rozès, N., 2000. Influence of phenolic compounds on the physiology of Oenococcus oeni from wine. J. Appl. Microbiol. 88, 1065-1071.

Ribéreau-Gayon, P., Glories, Y., Maujean, A., Dubardieu, D., 2000 Phenolic compounds. In: Handbook of Enology, vol. 2. Wiley, Chichester, pp. 129-183.

Sponholz, W.R., 1993. Wine spoilage by microorganisms. In: Fleet, G. (Ed.), Wine, Microbiology and Biotechnology. Harwood Academy Publishers, Chur, pp. 289-316.

Stead, D., 1993. The effect of hydroxycinnamic acids on the growth of wine-spoilage lactic acid bacteria. J. Appl. Microbiol. 75, 135-141.

van Vuuren, H.J.J., Dicks, L.M.T., 1993. Leuconostoc oenos: a review. Am. J. Enol. Vitic. 44, 99-112.

Vivas, N., Augustin, M., Lonvaud-Funel, A., 2000. Influence of oak wood and grape tannins on the lactic acid bacterium Oenococcus oeni (Leuconostoc oenos, 8413). J. Sci. Food Agric. 80, 1675-1678. 